\title{
Design e sustentabilidade ambiental: abordagens biológicas para inovar aplicadas a materiais têxteis
}

\author{
Design and environmental sustainability: biological approaches to innovate applied \\ to textile materials
}

\author{
BERGMANN, Márcia; Doutora; Puc-Rio \\ marciabergmann@gmail.com \\ MAGALHÃES, Cláudio; Doutor; Puc-Rio \\ claudio-design@puc-rio.br
}

\section{Resumo}

O respeito ao meio ambiente é um tema dominante no design contemporâneo e a natureza como fonte de ideias, recursos e soluções para problemas e necessidades humanas pode proporcionar inovações radicais. Por isso, o presente estudo busca estabelecer relações entre: design, abordagens biológicas para inovar, materiais têxteis e sustentabilidade ambiental. Para tal, foi realizada pesquisa bibliográfica e documental nos campos do design, engenharia têxtil e biologia. O tema é abordado em três seções: estratégias para o design colaborar para a sustentabilidade ambiental em materiais têxteis; maneiras de inovar por meio de abordagens biológicas biomimética e biotecnologia; e, integrando as duas primeiras, aplicações de abordagens biológicas a materiais têxteis. Assim, na tentativa de conciliar respeito à natureza, desenvolvimento econômico e visão criativa foi possível identificar perspectivas e desafios para o design de materiais têxteis ao adotar abordagens biológicas.

Palavras Chave: biomimética; biotecnologia; materiais têxteis e sustentabilidade ambiental.

\begin{abstract}
Respect for the environment is a dominant theme in contemporary design, and Nature as a source of ideas, resources and solutions to human problems and needs can provide radical innovations. This study seeks to establish relationships between: design, biological approaches to innovate, textile materials and environmental sustainability. For this end, bibliographic and documentary research was carried out in the fields of design, textile engineering and biology. The theme is addressed in three sections: strategies for design contribute for environmental sustainability in textile materials; and integrating the two previous sections, an investigation on applications of biological approaches to textile materials. Thus, in the attempt to reconcile respect for nature, economic development and creative vision, it was possible to identify perspectives and challenges for the design of textile materials by adopting biological approaches.
\end{abstract}

Keywords: biomimicry; biotechnology; textiles and environmental sustainability. 


\section{Introdução}

Estima-se que decisões tomadas durante as atividades projetuais sejam responsáveis por oitenta a noventa por cento dos custos ambientais e econômicos de um produto (GRAEDEL ET AL., 1995). Esse pressuposto estabelece uma relação explícita entre design e sustentabilidade ambiental. Logo, no âmbito da indústria têxtil, o design pode ser um impulsionador para o desenvolvimento de estratégias capazes de reduzir o impacto desse setor industrial no meio ambiente.

Entre as dez estratégias para o design lidar com a complexidade da sustentabilidade propostas pelo Textiles Environment Design - grupo de pesquisa associado ao Chelsea College of Arts (Londres/Inglaterra) - encontram-se duas associadas a abordagens biológicas (TED, 2018). A primeira refere-se ao design que utiliza sistemas de produção menos nocivos ao ambiente e destaca o uso de materiais e processos de base biológica. A segunda diz respeito ao design que encontra inspiração na natureza para encontrar soluções para os têxteis. Nesse sentido, o desenvolvimento de abordagens biológicas podem ser ferramentas poderosas em uma sociedade cujos novos paradigmas exigem novas estratégias de design.

Considerando que todos os agentes ao longo da cadeia têxtil compartilham as responsabilidades pelos problemas ambientais causados por ela (GREENPEACE, 2011; EC, 2013), torna-se importante inserir o design no contexto industrial. Assim, cabe salientar que a indústria têxtil do mesmo modo que é considerada relevante para a economia também destaca-se pelo impacto negativo no meio ambiente. No Brasil, por um lado, essa indústria representa $4,1 \%$ do total do PIB (TEXPERTS, 2015), é o quinto maior produtor têxtil do mundo; segundo maior empregador da indústria de transformação e possui como diferencial ser um dos poucos países que contempla a cadeia têxtil de modo completo: produção das fibras, fiação, tecelagem, beneficiamento, design, confecção e varejo (ABIT, 2017). Por outro lado, ela causa problemas de ordem ambiental por conta do considerável volume de residuos sólidos provenientes de processos industriais e de descarte pós-consumo. Para se ter uma noção, a indústria brasileira de moda e confecção, em 2012, foi responsável pela produção de 175 mil toneladas de residuos têxteis (ZONATTI, 2016).

Por tudo isso, o objetivo deste estudo é identificar perspectivas e desafios para o design na relação com a tríade "sustentabilidade ambiental - materiais têxteis - abordagens biológicas para inovação". Assim, são formuladas questões a serem respondidas. Como essas complexas relações afetam o futuro dos têxteis? Como os têxteis podem impactar menos o meio ambiente? Como o design pode contribuir neste contexto? Para tal, foi realizada pesquisa bibliográfica e documental sustentadas por dois eixos - o da biomimética e o da biotecnologia - nos campos do design, da engenharia têxtil e da biologia.

O artigo está estruturado em três seções: estratégias para o design colaborar para a sustentabilidade ambiental em materiais têxteis; maneiras de inovar por meio de abordagens biológicas; e, integrando as duas primeiras, uma investigação sobre aplicações de abordagens biológicas a materiais têxteis. Salienta-se que a abordagem do tema requer o entendimento de três conceitos fundamentais: (1) materiais têxteis são produtos compostos essencialmente por 
fios e fibras que - combinados - constituem tecidos, não tecidos ${ }^{1}$ e afins (NIELSON, 2007); (2) sustentabilidade ambiental procura preservar o meio ambiente e garantir o desenvolvimento econômico (KEELER E BURKE, 2010); (3) abordagens biológicas para inovar são modos de lidar com materiais e processos considerando a inspiração e/ou a utilização de organismos vivos - e seus derivados - para a solução de problemas (MONTANA-HOYOS E FIORENTINO, 2016).

\section{Integração entre design, sustentabilidade ambiental e materiais têxteis}

O impacto ambiental dos têxteis varia de acordo com o tipo de fibra utilizado (THOMPSON, 2015), mas não somente. Também são fatores influenciadores: a utilização de energia; as emissões de gases com efeito de estufa; a toxicidade dos processos de manufatura, incluindo produtos químicos pré-tratamento, corantes e acabamentos; o descarte de resíduos de produção e de produtos pós-consumo; o processamento de matérias-primas fósseis em fibras sintéticas; o uso intensivo de água; as contaminações por fertilizantes, pesticidas e herbicidas em fibras naturais (EC, 2013). Nessa conjuntura, a indústria têxtil precisa enfrentar os problemas associados à sustentabilidade ambiental ao desenvolver fibras e materiais que gerem impacto menor no meio ambiente; ao incentivar a reutilização e a reciclagem de materiais; ao promover processos que consumam menos água, energia, produtos químicos; ao evitar desperdícios; ao estimular projetos associados a novas práticas sociais, como a locação e venda de têxteis usados (EC, 2013; BRUNO, 2016).

Nesse panorama, compreende-se que o design possui compromisso com a sustentabilidade ambiental na indústria têxtil, especialmente ao assumir as implicações de suas decisões. Cabe ao design a função de escolher adequadamente as matérias-primas, pois elas influenciam significativamente o impacto ambiental dos produtos (GFA \& BCG, 2017). Assim, o design atua fundamentalmente buscando soluções mais eficazes ao implementar estratégias em quatro áreas na indústria têxtil:

- Design para reciclagem, ao eliminar barreiras para a aplicação de soluções em larga escala, por exemplo, ao evitar a mistura de fibras; ao optar pela incorporação de materiais reciclados na composição dos produtos; ao projetar têxteis que considerem a desmontagem de suas partes (THOMPSON, 2015; BRUNO, 2016; GFA \& BCG, 2017; TED, 2018).

- Design para a redução, ao minimizar o desperdício tanto no pré quanto no pósconsumo; ao diminuir a utilização de recursos, como energia e água em todas as etapas do ciclo de vida dos produtos; ao reduzir o uso de insumos nocivos ao meio ambiente (GFA \& BCG, 2017; TED, 2018).

- Design para reutilização, ao estender o ciclo de vida dos produtos; ao incentivar o reuso de têxteis e o comércio desses produtos usados; ao projetar considerando possibilidades de adaptação, de manutenção e de reparo dos materiais; ao evitar o descarte e a destinação para aterros sanitários (THOMPSON, 2015; GFA \& BCG, 2017; TED, 2018).

\footnotetext{
${ }^{1}$ É produzido a partir de fibras desorientadas que são aglomeradas e fixadas, sem fiação, tecelagem, malharia, ou outro processo de fabricação têxtil.
} 
- Design para o desenvolvimento de materiais, ao projetar fibras inovadoras artificiais ou naturais - que evitem as externalidades negativas de outras matériasprimas e transcendam os atributos tradicionais dos têxteis (GFA \& BCG, 2017; TED, 2018).

Desta forma, a reciclagem, a redução, a reutilização e o desenvolvimento de materiais configuram objetos do design ao abordar problemas e soluções associados a tecnologias, a produtos, a comportamento do consumidor e a estratégias de negócios, bem como, ao estabelecer novas relações entre têxteis e sustentabilidade ambiental.

\section{Inovação e abordagens biológicas}

No século XXI, alternativas advindas do campo da biologia têm sido consideradas importantes fontes de inovação, seja com foco na bioinspiração (ou biomimética), isto é, inspiração em estruturas encontradas na natureza, ou seja por meio do uso de biotecnologias, isto é, tecnologias que utilizam organismos vivos e seus derivados (MYERS, 2014). Isso porque, na atualidade, admite-se a possibilidade de beneficiar-se da constante mutação das propriedades naturais (MYERS, 2014) em oposição ao uso de processos orientados para o controle das forças da natureza, como as tecnologias que apoiaram os desenvolvimentos industriais até o século XX: química, mecânica, eletrônica e de energia (KAZAZIAN, 2005; MYERS, 2014 MONTANA-HOYOS E FIORENTINO, 2016). Indústrias de base apoiadas nessas tecnologias continuam sendo relevantes para o modo de produção contemporâneo. No entanto, as preocupações ambientais impactam cada vez mais os desempenhos e as reputações desses setores industriais tradicionais, assim como elas estimulam o interesse por abordagens inovadoras e menos nocivas à natureza, como as biológicas.

A bioinspiração é uma abordagem apoiada na vida natural para a solução de problemas de design (MYERS, 2014). Ela não é uma estratégia nova, pois possui antecedentes nas artes, na arquitetura e na engenharia, porém se consolidou a partir de meados do século XX com iniciativas associadas aos estudos de biomimética. A ideia central da biomimética é que a natureza - após bilhões de anos de evolução - resolveu muitos dos problemas que ainda precisam ser solucionados pela humanidade. Ela se apropria desse conhecimento como inspiração e também como medida e mentoria, preocupando-se não apenas com formas de extrair recursos, mas enfatizando o que se pode aprender com os processos naturais (BENYUS, 1997).

No que se refere à sustentabilidade ambiental, a biomimética abrange projetos que envolvem eficiência energética, eliminação de resíduos e de desperdício, assim como a proteção da biodiversidade, orientando o foco da bioinspiração para além de escolhas estéticas (MYERS, 2014). Um exemplo é a circulação de materiais dentro de um ecossistema, transformando o detrito de um agente em nutriente para outro. Tal conceito foi inspirado na capacidade das florestas não produzirem lixo e tem sido adotado por organizações de diversos setores (BENYUS, 1997). Nesse contexto, o modelo denominado do berço ao berço (ou circular) propõe uma produção têxtil continuamente reciclada, portanto, sem emissão de resíduos no meio ambiente (WHITEFOOT, 2009). 
Esta mudança na forma de circulação de materiais em um sistema produtivo demanda novos comportamentos de todos os campos do conhecimento envolvidos, ao requerer uma abordagem holística e exigir mais responsabilidade durante todo o ciclo de vida dos produtos industriais (BEYLERIAN E DENT, 2007). O êxito do modelo circular depende de vários fatores no que diz respeito à atuação do design. Entre eles: novas práticas projetuais que considerem não só os resíduos de um sistema como nutriente para o outro, mas que levem em conta as consequências desta premissa; identificação de tecnologias emergentes que permitam esse intercâmbio entre organizações; comunicação do valor destas iniciativas para o consumidor; por fim, aprimoramento da comunicação entre todos os agentes envolvidos (MAZZONI, 2014; FLETCHER, 2011).

Além da biomimética, há outra abordagem biológica: a biotecnologia, que pressupõe promover a saúde humana e a sustentabilidade ecológica ao projetar a partir de fundamentos da biologia e ao produzir por meio de processos biológicos que se integram a sistemas industriais (MYERS, 2014). A biotecnologia utiliza organismos vivos - plantas, animais e microrganismos - ou seus derivados e seus ecossistemas para corrigir situações que não funcionam de acordo com os parâmetros contemporâneos de eficiência ecológica, assim como, para produzir novos materiais.

A biotecnologia favorece a criação de produtos híbridos, como resultado de colaboração transdisciplinar, principalmente entre a biologia e a nanotecnologia (MYERS, 2014). Isso porque a manipulação de microorganismos no nível celular e molecular possibilita desenvolver materiais disruptivos, que apresentam, por exemplo: alteração de cores superficiais, liberação de odores, emissão de luz, detecção de poluição e de substâncias insalubres (QUINN, 2013; MYERS, 2014; MONTANA-HOYOS E FIORENTINO, 2016).

Os biomateriais ${ }^{2}$, isto é, materiais que se referem especificamente à incorporação de organismos vivos como componentes essenciais aos produtos, também possuem uma dimensão ecológica (MYERS, 2014). Eles permitem a redução do consumo de recursos, a diminuição do uso de produtos químicos, a restrição no descarte de resíduos e o aumento da eficiência em processos fabris (MYERS, 2014; MONTANA-HOYOS E FIORENTINO, 2016).

Ambas as abordagens biológicas - bioinspiradas e biotecnológicas - oferecem benefícios, mas não estão livres de riscos, erros e controvérsias (MYERS, 2014). A biomimética é alvo de desaprovação quando seu uso é orientado somente para efeitos decorativos (MYERS, 2014). A biotecnologia é julgada por adotar um paradigma industrial tradicional, em que o principal objetivo é o crescimento econômico e em que as soluções não tratam das origens do problema ambiental, mas as consequências dele (MONTANA-HOYOS E FIORENTINO, 2016).

Apesar de tudo isso e embora ainda seja uma área de atuação predominantemente limitada a experimentações, projetos conceituais e pesquisas em universidades e em laboratórios, a utilização de abordagens biológicas com foco na sustentabilidade ambiental pode gerar um período virtuoso e criativo para o design (MYERS, 2014). O cenário é promissor porque, de modo amplo, é crescente a conscientização da sociedade quanto a sua responsabilidade pelo

\footnotetext{
${ }^{2}$ Os biomateriais excluem os biotêxteis, que são estruturas compostas de fibras têxteis projetadas para uso em ambientes biológicos específicos, onde o desempenho delas depende da compatibilidade com células e fluidos biológicos, como dispositivos implantáveis, suturas cirúrgicas e próteses (BIOTEXTILES, 2016).
} 
desenvolvimento econômico em equilíbrio com questões ambientais e com o bem-estar das pessoas (MONTANA-HOYOS E FIORENTINO, 2016) e, de modo específico, as técnicas de modificação genética estão se tornando mais acessíveis, na medida em que começam a se tornar economicamente competitivas em um número cada vez maior de setores industriais (MYERS, 2014).

\section{Biotecnologia e biomimética aplicadas a materiais têxteis}

A aplicação de abordagens biotecnológicas e bioinspiradas em projetos de materiais têxteis ainda é incipiente, principalmente no que diz respeito ao aproveitamento do potencial de sustentabilidade ecológica de ambas. Contudo, apesar dos exemplos ainda serem limitados na quantidade, eles são representativos no que diz respeito às possibilidades criativas, particularmente nos casos de utilização de biotecnologias.

$\mathrm{Na}$ indústria têxtil, o design de produtos tem utilizado estratégias para inovar com base em materiais exógenos. Fios e fibras são combinados a produtos cerâmicos, vítreos e até metálicos, desenvolvendo revestimentos híbridos (O'MAHONY, 2006). Mais recentemente, têxteis são associados à celulose ${ }^{3}$ bacteriana, isto é, fibras geradas por meio de culturas microbiológicas (COSTA ET AL., 2017). Essas culturas referem-se a processos naturais de multiplicação de microorganismos vivos, que são capazes de gerar membranas fibrosas com características similares a um tecido não tecido, dando origem a materiais biotecnológicos (COSTA ET AL., 2017).

Considerando que, na natureza, o crescimento é o principal meio de produção em vez da fabricação (EADIE \& GHOSH, 2011), os materiais biotecnológicos para uso têxtil não são dependentes de processos tradicionais da indústria, mas se desenvolvem essencialmente por meio de processos biológicos naturais, como a fermentação (SURJO, 2006). Ela favorece o crescimento de celulose bacteriana e permite a interrupção do processo ao se privar os microorganismos de seus nutrientes, para o material posteriormente receber beneficiamento (COSTA ET AL., 2017).

As fibras de celulose bacteriana ainda não atingiram escala industrial no setor têxtil (COSTA ET AL., 2017). Mas, materiais produzidos por processos biológicos naturais fomentam intensa pesquisa e experimentação (BRUNO, 2016). Entre os exemplos de protótipos, há membranas produzidas a partir de chá verde (Figura 1), que dão origem a um material muito similar ao couro bovino e permite o corte, a costura e o tingimento (MYERS, 2014; SDF, 2016); bem como há fibras produzidas a partir da fermentação do leite de vaca impróprio para o consumo humano (SDF, 2016). Nesse caso, após o processo biológico, o material é transformado em pó e misturado com

\footnotetext{
${ }^{3}$ É importante enfatizar a diferença entre materiais têxteis à base de celulose bacteriana e polímeros à base de celulose vegetal. Embora funcionais e oportunos, os últimos não atendem à definição de biotecnologias porque, resumidamente, não utilizam organismos vivos e derivados em seus processos de produção (MYERS, 2014), mesmo sendo materiais produzidos por meio de uma fonte biológica (ROWE, 2009) e apesar da sua compatibilidade com a noção de sustentabilidade ambiental (RÜEGG, 2015). Em diferentes estágios de pesquisa, desenvolvimento, produção e comercialização, existem diversos exemplos têxteis à base de polímeros de celulose vegetal: fibras de polpa de madeira, bambu, milho, mamona (COLCHESTER, 2007); filamentos de poliamida 6.6 com glicose e outras matériasprimas renováveis (GFA \& BCG, 2017); materiais produzidos a partir de resíduos, como a gelatina proveniente do colágeno de gado de corte (RÜEGG, 2015), como sobras do cultivo de abacaxis e de bananas (SDF, 2016).
} 
outros ingredientes naturais para, então, obter-se a forma de fio (QMILKFIBER, 2011). Esse material não possui produtos químicos em sua composição, consome pouca água durante o processo e, ao ser lavado, seca duas vezes mais rápido do que o algodão (SDF, 2016).

Figura 1 - Membranas compostas por celulose bacteriana à base de chá verde e aplicação em vestuário.

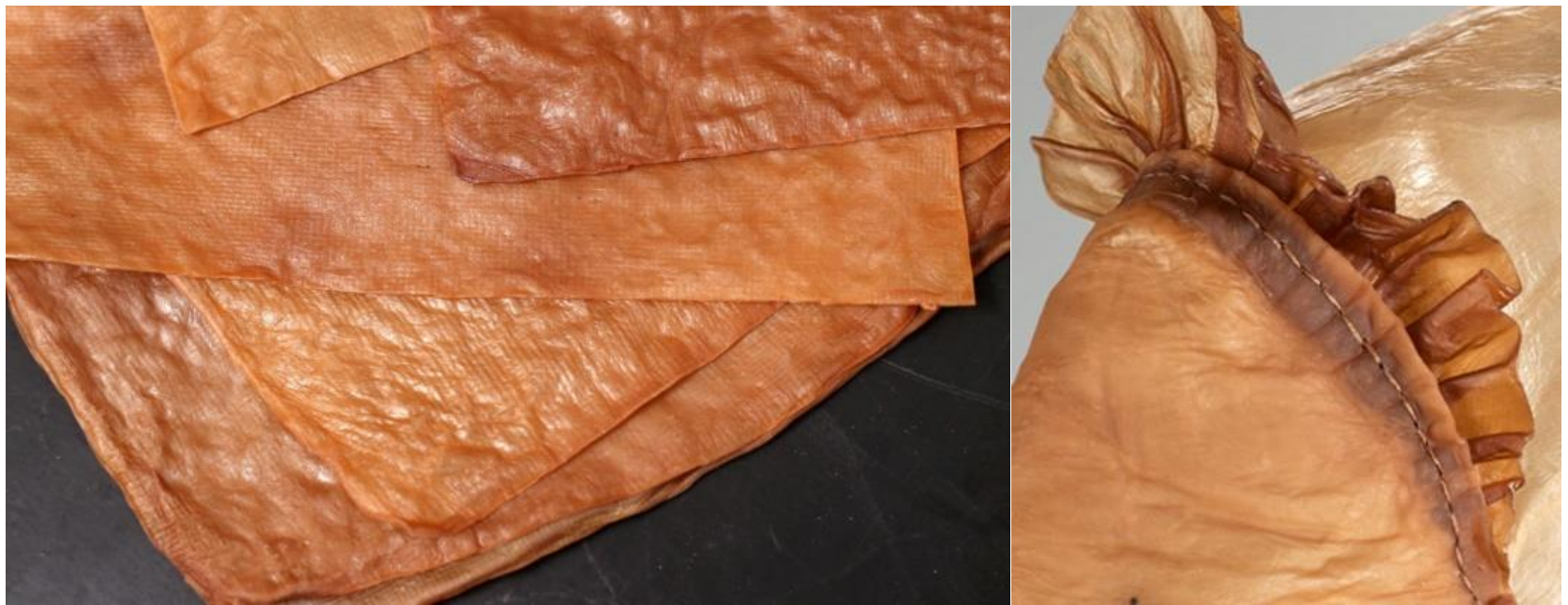

Fonte: Ecouterre (2014).

No entanto, existem materiais ainda mais inovadores do que as membranas à base de fibras de celulose bacteriana. Eles admitem a ideia de superfícies semivivas ao questionarem aspectos estéticos e simbólicos convencionais; e, ainda, ao proporcionarem novos tipos de experiências comportamentais, emocionais e sensoriais (SURJO, 2006). Nesse contexto disruptivo, destacam-se dois exemplos de projetos conceituais. Um é o tecido de microalgas vivas que realizariam fotossíntese e gerariam bioluminescência, interagiriam e responderiam ao ambiente (SAWA, 2014). O outro é a proposta de cultivar tecidos por meio de plantas geneticamente modificadas (Figura 2), que gerariam materiais customizados e com aparência rendada (QUINN, 2013).

Figura 2 - Detalhes de projeto conceitual de plantas geneticamente modificadas para gerar materiais rendados.

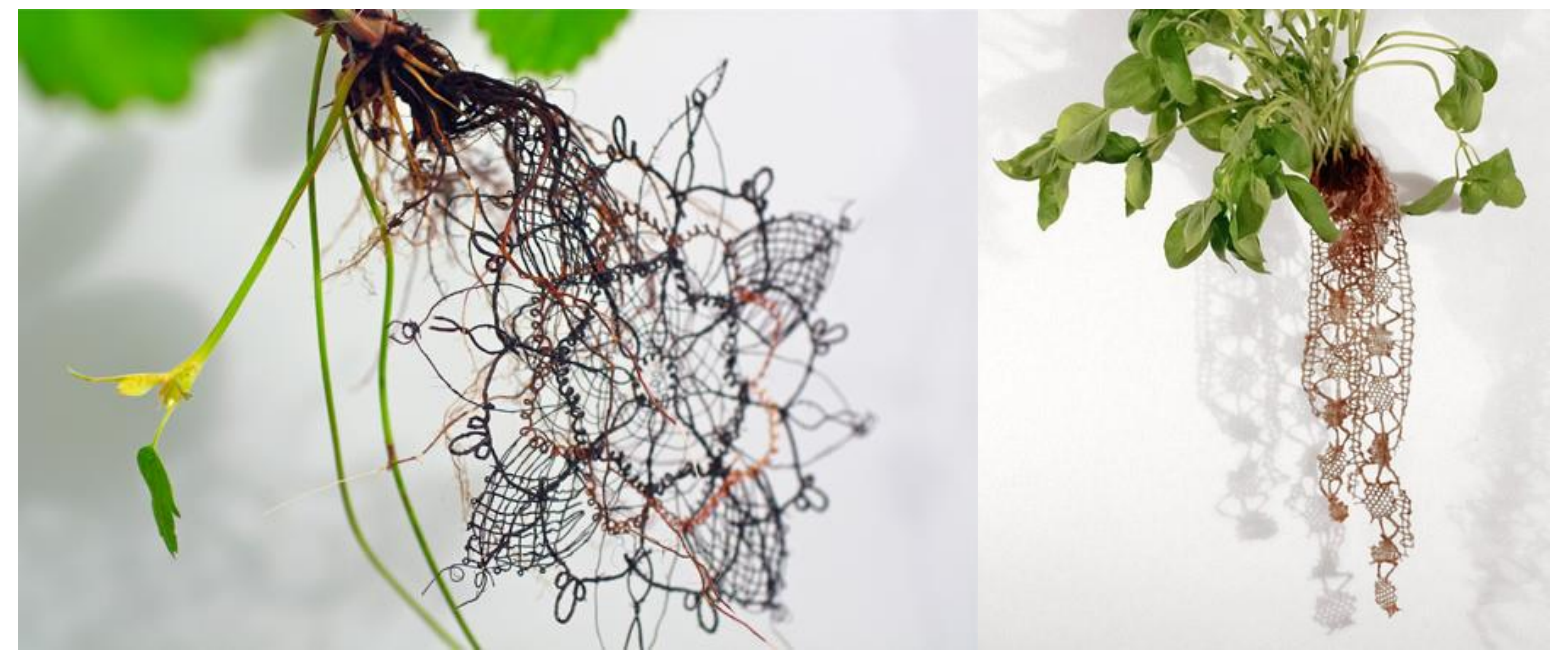

Fonte: This is alive (2012) 
Vale destacar que os exemplos citados, enquanto protótipos, projetos conceituais e produtos de pequena escala para nichos, não são meramente substitutos para materiais têxteis convencionais, pois eles expandem as fronteiras entre têxteis e outros grupos de materiais (CASTLE, 2006). Aparentemente insólitos, no futuro, eles poderão se tornar materiais comuns (SURJO, 2006), desde que apresentem soluções para aspectos técnicos, como a conservação do metabolismo de organismos vivos fora de seus habitats naturais; e para aspectos comportamentais, como o entendimento de que o convívio com microorganismos pode ser saudável (MYERS, 2014).

Quanto à segunda abordagem biológica para inovar - a biomimética - é importante ressaltar que a natureza desenvolveu superfícies funcionais e estruturas fibrosas para a sobrevivência de organismos que podem servir de modelos para materiais têxteis (BRUNO, 2016). Existem diversos exemplos de aplicação dos princípios de biomimética em materiais têxteis. Entre eles: (1) ० Velcro ${ }^{\circledR}$ e suas duas partes aderentes e tracionadas, que foram inspiradas na forma de algumas espécies de vegetais; (2) roupas para prática da natação que oferecem excelente hidrodinâmica, já que o tecido foi desenvolvido a partir da observação dos dentículos da pele dos tubarões; (3) tecidos autolimpantes compostos por micropilosidades projetadas de acordo com características superficiais de plantas, como o Lótus; (4) peças de vestuário que regulam a temperatura corporal, pois os tecidos são compostos por fibras que dilatam-se e contraem-se, inspiradas em mecanismos de liberação de sementes de árvores coníferas (CARVALHO, 2004), somente para citar alguns.

Além dos casos clássicos, a pesquisa relacionada à aplicação de princípios biomiméticos em materiais têxteis continua evoluindo. Estudos mais recentes exploram o potencial de inspiração na natureza para o desenvolvimento de acabamentos superficiais, como tecidos bioluminescentes por meio de bactérias específicas; assim como, o projeto de têxteis biodegradáveis, permitindo a absorção pelo meio ambiente quando descartados, por exemplo (MYERS, 2014; BRUNO, 2016; COSTA ET AL., 2017).

Contudo, a associação entre sustentabilidade ambiental e materiais têxteis com a biomimética gera exemplos escassos de produtos que percorrem toda a cadeia têxtil e chegam ao mercado. Nesta conjuntura, embora a produção em larga escala tenha sido interrompida em $2011^{4}$, destaca-se a fabricação de tecido (Figura 3) inspirado em microescamas refletoras de asas de algumas espécies de borboletas (LACERDA ET AL., 2012). Esse revestimento têxtil reduziu o consumo de energia e de produtos químicos, uma vez que a cor era criada com base em diferentes espessuras e diversos formatos de fibras e não, a partir da aplicação de pigmentos (BEN, 2015).

\footnotetext{
${ }^{4}$ Não foram encontrados dados que justifiquem a interrupção, mas especula-se que seja devido à inadequação entre preço e demanda.
} 
Figura 3 - Tecido colorido sem pigmentos inspirado em asas de borboletas (detalhe e aplicado no vestuário).

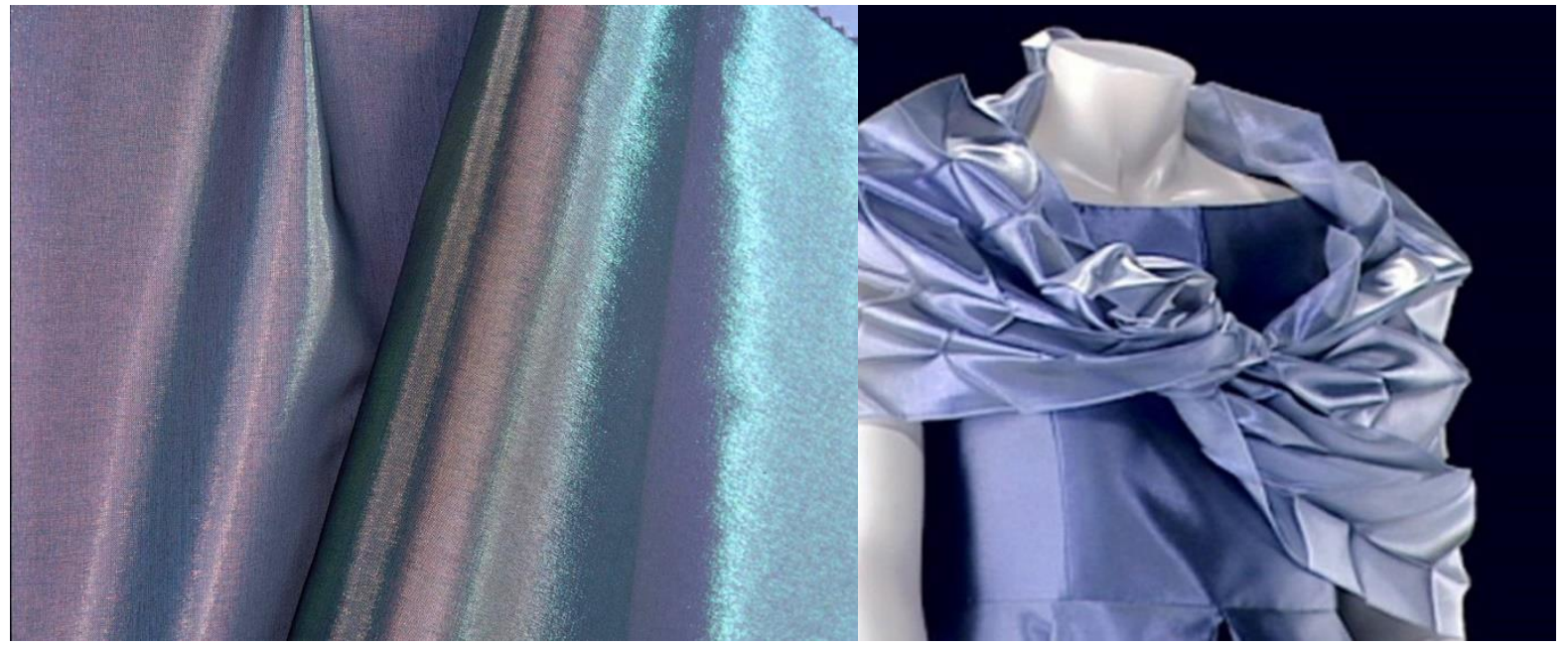

Fonte: Transmaterial (2010)

Em outro exemplo - especificamente em revestimentos têxteis para piso conhecidos como carpetes modulares (Figura 4) - observa-se o propósito de reduzir o descarte de resíduos por meio do desenvolvimento de padronagens randômicas e inspiradas em formas e texturas do solo de florestas (LACERDA ET AL., 2012). Tal e qual uma camuflagem, o design de superfície dos módulos reduz em um terço as sobras de instalação, além de facilitar a remoção seletiva de áreas desgastadas pelo uso, ampliando a vida útil da maior parte do carpete instalado (RICHTER, 2006; BEYLERIAN E DENT, 2007).

Figura 4 - Carpetes modulares com padronagem inspirada no solo de florestas (aplicado no ambiente e detalhe)

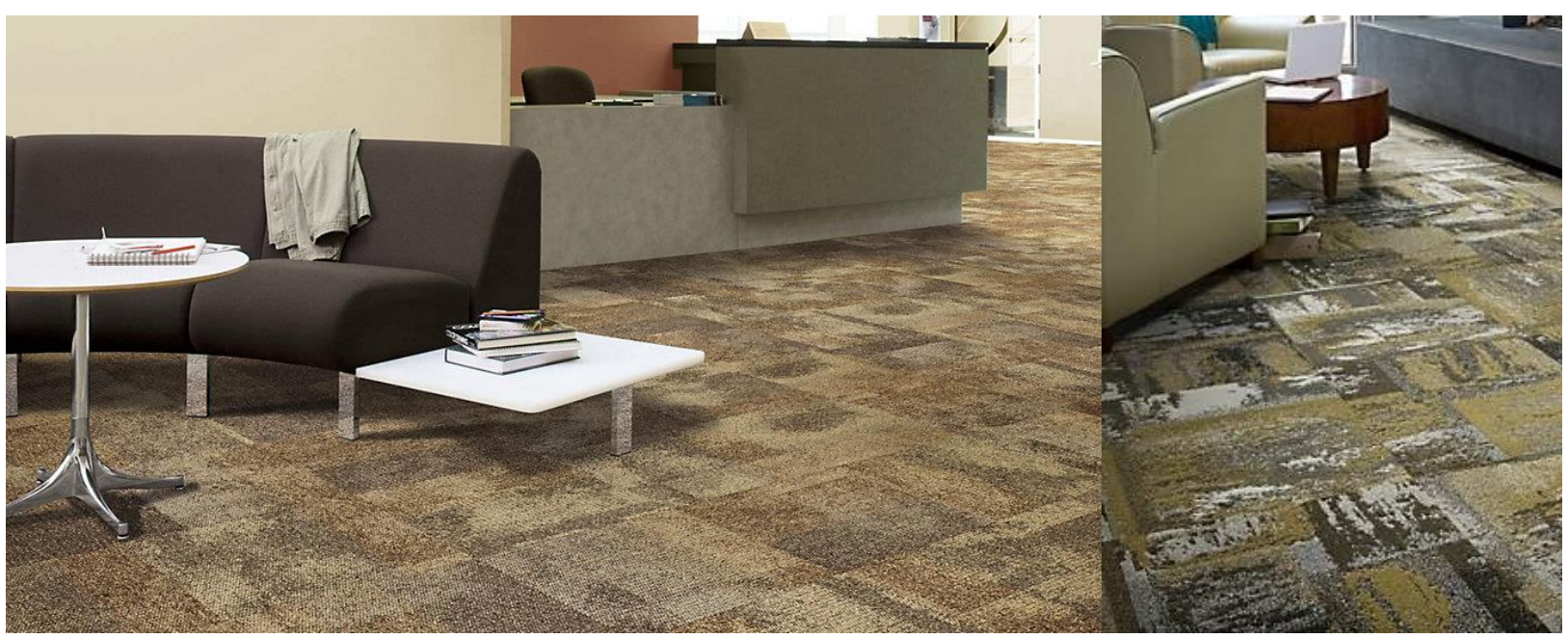

Fonte: Interface (2015) 
Além da aplicação no projeto de produto, uma das principais contribuições da biomimética para a indústria têxtil ocorre no processo de gestão e circulação de materiais. Trata-se do sistema do berço ao berço, que é sustentado pela noção de ciclo biológico natural (THOMPSON, 2015). De modo resumido, nesse sistema os produtos descartados retornam como matéria-prima para a uma nova etapa de produção.

Iniciativas bem-sucedidas da adoção dos princípios do sistema do berço ao berço são observadas em empresas globais da indústria de revestimentos têxteis para piso. Algumas delas inclusive a maior fabricante de carpetes modulares - investem em projetos de certificação de produção no paradigma circular. Isso porque elas incorporaram a sustentabilidade ambiental as suas estratégias organizacionais, reconhecendo o significativo impacto no meio ambiente dos grandes volumes produzidos e do uso de fibras manufaturadas e sintéticas (CTOCl, 2013). Porém, mais uma vez, esses casos ainda representam exceções. Embora seja uma prática reconhecida na área têxtil desde 1995 (THOMPSON, 2015), a sua relevância para a sustentabilidade ambiental ainda requer escala e exige a intensificação de esforços coordenados entre os agentes da cadeia têxtil (GFA \& BCG, 2017).

O respeito ao meio ambiente é um tema dominante na contemporaneidade e o design para a sustentabilidade apoiado em abordagens biológicas é uma tendência que possui uma face conhecida - a biomimética - e uma face emergente - a biotecnologia. Ambas podem ser implementadas em projetos de design por meio de diversas estratégias, mas a utilização dessas abordagens especificamente em materiais têxteis - conforme exemplos de produtos e processos apresentados - depende de mudanças culturais, capacidade de investimento, visão coletiva e de longo prazo.

\section{Perspectivas e desafios}

O presente estudo buscou estabelecer relações entre: design, abordagens biológicas para inovar, materiais têxteis e sustentabilidade ambiental. Assim, primeiro foram identificadas estratégias para o design colaborar para a sustentabilidade ambiental em materiais têxteis. Depois, baseados em abordagens biológicas, foram apontados modos de se inovar por meio delas. Por fim, foram apresentados casos práticos de utilização dessas abordagens, que simultaneamente são aplicadas a materiais têxteis e não negligenciam o meio ambiente. Desta forma, ao identificar conexões entre os conteúdos abordados, foi possível inferir sobre perspectivas para os têxteis e o impacto deles no meio ambiente, bem como sobre desafios para o design contribuir neste contexto ao relacionar-se com produção, consumo e ciência.

Quanto ao futuro dos materiais têxteis ao serem submetidos às abordagens de biotecnologia e de biomimética, compreende-se que as inovações nesta área de pesquisa são capazes de expandir as fronteiras dessa categoria. As soluções desenvolvidas em protótipos e projetos conceituais são originais e instigantes, possibilitando antever a transformação da natureza têxtil por meio da hibridização de materiais. Permitindo-se aos têxteis a transformação em materiais dinâmicos e mutáveis, principalmente aqueles utilizados no vestuário. Como extensões da pele e, em alguns casos, associados a organismos vivos, poderão surgir relações de simbiose entre tecidos e pessoas. 
Entende-se que os têxteis são relevantes porque constituem uma ampla variedade de materiais utilizados em diferentes domínios e para diversas finalidades, seja como insumo, produto semiacabado ou como produto final. Porém, nem por isso pode-se deixar de questionar a sua repercussão negativa no meio ambiente. Assim, no que se refere à sustentabilidade ambiental, os materiais desenvolvidos a partir de abordagens biológicas apontam para soluções biodegradáveis e recicláveis, em uma escala superior dos demais têxteis; e para menor dependência de processos fabris convencionais e geralmente poluidores.

Sobre as contribuições do design neste cenário, compreende-se que abordagens biológicas são capazes de promover a elaboração de um circulo virtuoso entre materiais têxteis e sustentabilidade ambiental. Surgem oportunidades para reconfigurar o design de materiais têxteis, alterar meios de produção, transformar experiências de uso e oferecer melhor desempenho ecológico por meio de projetos de biomimética e de utilização de biotecnologia.

A manipulação criativa de comunidades de microorganismos por meio do design pode subverter convenções e transformar e ressignificar materiais tradicionais para promover mudanças positivas e orientadas para a sustentabilidade ambiental. Evidentemente, sem desconsiderar os obstáculos vinculados ao desenvolvimento de mecanismos para controlar as ações e as reações de têxteis biotecnologicamente produzidos.

Possivelmente, os desafios não ficam restritos a aspectos técnicos. Afinal, há de se considerar que a necessidade de se desenvolver projetos que conciliem viabilidade comercial e sustentabilidade ambiental. Dessa forma, é preciso levar em conta as relações do design com a indústria, com o consumidor e com profissionais de outros campos do conhecimento. No primeiro caso, podem surgir conflitos e propósitos divergentes entre o design e a os meios de produção se a preocupação com o meio ambiente não permear a orientação estratégica das organizações. Talvez caiba ao design, assim, assumir um papel de coordenação na busca pelo equilíbrio entre a eficiência operacional imediata e as escolhas de projeto associadas à inovação e à redução do impacto ambiental no futuro.

No segundo caso, há de se considerar a resistência dos consumidores a produtos disruptivos. Desse modo, é preciso levar em conta que uma necessidade de mercado pode impulsionar a inovação, mas a uma ideia inovadora também pode ser uma força motriz para gerar novos comportamentos. Desse modo, pode caber ao design o desenvolvimento de produtos funcionais, atraentes e passíveis de compreensão por parte do público-alvo; estimulando-o a aceitar e valorizar estéticas incomuns; além de contribuir para a conscientização da ponta da cadeia de valor para a sua responsabilidade quanto à adoção de comportamentos de consumo sustentáveis.

Já no terceiro caso, o design deve ponderar a sua integração a um esforço coletivo e transdisciplinar, no qual o diálogo com outros campos possivelmente demandará o compartilhamento de conhecimento e o preenchimento de lacunas de vocabulário. Vale salientar que - a despeito da transdisciplinaridade de projetos de design com abordagens biológicas para inovar - especula-se que não se deve desprezar a incorporação da biologia ao currículo dos cursos de design futuramente.

Os desafios não são modestos, mas as oportunidades que podem surgir da tríade "sustentabilidade ambiental - materiais têxteis - abordagens biológicas para inovação" são promissoras para o design. Constata-se que o tema é complexo e requer aprofundamento, 
suscitando novos estudos. Entre as possibilidades, considera-se a realização de pesquisas apoiadas em bioinspiração e em biotecnologias baseadas em características da biodiversidade brasileira. Do mesmo modo, conjectura-se o que o potencial disruptivo da Indústria 4.0 pode oferecer para essa área de pesquisa e prática do design. Logo, novas investigações poderão incorporar contextos biológicos e têxteis a novas tecnologias de automação, autoprodução, informação e comunicação, por exemplo.

A despeito de outras possibilidades de estudo, na tentativa de conciliar desenvolvimento econômico, respeito à natureza e visão criativa, o presente artigo permitiu compreender que é necessário que todos os envolvidos na cadeia têxtil estejam preparados para se adaptar a novos paradigmas. Isso posto, limitações para o tema estão relacionadas à imaginação dos designers, à aceitação dos consumidores, à capacidade de investimento da indústria e ao compromisso de todos com o futuro e com a inovação ambientalmente sustentável.

\section{Referências}

ASSOCIAÇÃO BRASILEIRA DA INDÚSTRIA TÊXTIL E DE CONFECÇÃO (ABIT). Dados gerais do setor referentes a 2017. Disponível em: <http://www.abit.org.br/cont/perfil-do-setor>. Acesso em 18 mar. 2018

BENYUS, J. M. Biomimética: inovação inspirada pela natureza. São Paulo: Cultrix, 1997.

BEYLERIAN, G. M.; DENT, A. Ultramaterials: how materials innovation is changing the world. London: Thames e Hudson, 2007.

BIOMIMICRY EDUCATION NETWORK (BEN). Colored fibers and fabric without chemical dyes, 2015. Disponível em: <https://asknature.org/idea/morphotex-structural-coloredfibers/\#.WsPgUljwblU>. Acesso em: 17 mar. 2018.

BIOTEXTILE PRODUCT DEVELOPMENT (BPD). Introduction to Biotextiles, 2016. Disponível em: <https://biotextiles2016.wordpress.com/2016/03/14/introduction-to-biotextiles/>. Acesso em: 10 mar. 2018.

BRUNO, F. S. A. Quarta Revolução Industrial do Setor Têxtil e de Confecção: a visão de futuro para 2030. São Paulo: Estação das Letras e Cores, 2016, 149p. Relatório Técnico. Disponível em: < http://www.abit.org.br/uploads/arquivos/A_quarta_revolucao_industrial_do_setor_textil_e_de_c onfeccao.pdf>. Acesso em: 18 abr. 2017.

CARVALHO, M. J. S. Tramas que o design tece: têxteis do novo milênio, têxteis técnicos e inteligentes. Porto, 2004. Dissertação (Mestrado). Faculdade de Engenharia, Universidade do Porto.

CASTLE, H. Architecture + Textiles = Architextiles. In: Architextiles. London: Wiley, 2006.

COLCHESTER, C. Textiles today: a global survey of trends and traditions. London: Thames e Hudson, 2007.

COSTA, A. F. S.; ROCHA, M. A. V.; SARUBBO, L. A. Bacterial celulose: na ecofriendly biotextile. International Journal of Textile and Fashion Technology (IJTFT) v.7, n.1, p. 11-26, 2017. Disponível em: https://www.researchgate.net/publication/314234769_REVIEW_BACTERIAL_CELLULOSE_AN_ECOFRIENDLY_BIOTEXTILE>. Acesso em 23 mar. 2018. 
CRADLE TO CRADLE INSTITUTE (CtoCl). Healthier flooring, 2013. Disponível em: <https://www.c2ccertified.org/innovation-stories/desso>. Acesso em 10 mar. 2018.

DENT, A. H.; SHERR, L, Material innovation: product design. Thames e Hudson, 2014.

EADIE, L.; GHOSH, T. K. Biomimicry in textiles: past, present and potential. An overview. J R Soc Interface, v. 8, n. 59, p. 761-775, 2011.

ECOUTERRE. Faux leather made from fermented tea, 2014. Disponível em: $<$ http://www.ecouterre.com/faux-leather-made-from-fermented-tea-could-revolutionizefashion/>. Acesso em: 17 mar. 2018.

EUROPEAN COMMUNITY (EC). Retail Forum for Sustainability, n.11, 2013. Disponível em: <http://ec.europa.eu/environment/industry/retail/pdf/issue_paper_textiles.pdf>. Acesso em 17 mar. 2018.

FLETCHER, K., Grose, L. Moda e Sustentabilidade: design para mudança. São Paulo: Ed. Senac, 2011.

GLOBAL FASHION AGENDA; THE BOSTON CONSULTING GROUP (GFA \& BCG). Pulse of fashion industry, 2017. Disponível em: <http://globalfashionagenda.com/wpcontent/uploads/2017/05/Pulse-of-the-Fashion-Industry_2017.pdf>. Acesso em: 17 mar. 2018.

GRAEDEL, T. E., REAVES, C. P, SEKUTOWSKI J. C. Green product design. AT\&T Technical Journal, nov./dec., p. 18-25, 1995.

GREENPEACE. Detox My Fashion - Entenda o caso, 2011. Disponível em: <http://www.greenpeace.org/brasil/pt/O-que-fazemos/Toxicos/intro/>. Acesso em: 19 mar. 2018.

INTERFACE. Carpete Modular, 2018. Disponível em: https://www.interface.com/LA/pt-BR/carpetemodular/featured>. Acesso em 19 mar. 2018.

INTERFACE. Tac Tiles, 2015. Disponível em: <http://www.interface.com/US/enUS/about/markets/Higher-Education-Modular-Carpet-Tile>. acesso em: 23 mar. 2018.

KAZAZIAN, T.(Org.) Haverá a idade das coisas leves: design e desenvolvimento sustentável. São Paulo: Senac, 2005.

KEELER, M., BURKE, M, Fundamentos de projeto de edificações sustentáveis. Porto Alegre: Bookman, 2010.

LACERDA, C., SORANSO, P, FANGUEIRO, R. O contexto biomimético aplicado ao design de superfícies Têxteis. REDIGE, v. 3, n. 03, 2012. Disponível em: <https://designlyn.files.wordpress.com/2014/04/155-724-1-pb.pdf>. Acesso em: 14 mar. 2018.

MAZZONI, M. Four lessons the apparel industry can learn from carpet-makers. Disponível em: <http://www.triplepundit.com/2014/06/4-lessons-apparel-industry-can-learn-carpet-makersclosed-loop/>. Acesso em: 12 de novembro de 2014.

MONTANA-HOYOS, C.; FIORENTINO, C. Bio-Utilization, Bio-Inspiration and Bio-Affiliation in Design for Sustainability: Biotechnology, Biomimicry and Biophilic Design. The international Journal of Designed Objects, v. 10, n.3, 2016.

MYERS, W. Biodesign: nature, Science, creativity. London: Thames e Hudson, 2014. 
NIELSON, K. J. Interior Textiles: fabrics, application e historic style. Hoboken: Wiley, 2007.

O'MAHONY, M. Textiles for 21st Century living. In: Architextiles. London: Wiley, 2006.

QUINN, B. Textile Visionaires: innovation and sustainability in textile design. London: Laurence King, 2013.

RICHTER, D. Camouflage as aesthetic sustainability. In: Architextiles. London: Wiley, 2006.

ROWE, T. Interior textiles: design and developments. Woodhead Publishing in textiles: n. 92. 2009.

RÜEGG, P. Yarn from slaughterhouse waste, 2015. Disponível em: <https://www.ethz.ch/en/newsand-events/eth-news/news/2015/07/yarn-from-slaughterhouse-waste.html>. Acesso em: 23 mar. 2018.

SAWA, M In: MYERS, W. Biodesign: nature, Science, creativity. London: Thames \& Hudson, 2014.

SLOW DOWN FASHION (SDF). Matérias-primas inovadoras na indústria da moda, 2016. Disponível em: $\quad$ https://www.slowdownfashion.com.br/single-post/2016/07/29/Mat\%C3\%A9riasprimasinovadoras-na-ind\%C3\%BAstria-da-moda>. Acesso em: 15 mar. 2018.

SURJO, S. Bio-tissue hotel. In: Architextiles. London: Wiley, 2006.

TEXPERTS. Special Report: Brazil - Current Scenario and its textile business, 2015. Disponível em: $<$ http://www.thetexperts.com/market-watch/special-report-brazil-current-scenario-and-its-textilebusiness/>. Acesso em: 17 mar. 2018.

TEXTILES ENVIRONMENT DESIGN (TED). The Ten, 2018. Disponível em: <http://www.tedresearch.net/teds-ten-aims/>. Acesso em: 24 mar. 2018

THIS IS ALIVE. To biofacture textiles, 2012. Disponível em: <http://thisisalive.com/biolace/>. Acesso em: 23 set. 2017.

THOMPSON, R. Materiais sustentáveis, processos e produção. São Paulo: Senac, 2015.

TRANSMATERIAL. Morphotex: Chromagenic fiber, 2010. Disponível em: http://transmaterial.net/morphotex/. Acesso em 17 nov. 2017.

WHITEFOOT, D. Carpet types and requirements. Cambridge: Woodhead Publishing in Textiles: Number 87, 2009.

ZONATTI, W. F. Geração de Resíduos sólidos da industria brasileira têxtil e de confecção: materiais e processos para reuso e reciclagem. São Paulo, 2016. Tese (Doutorado). Escola de Artes, Ciências e Humanidades, Universidade de São Paulo. 